\title{
Optical coherence tomography in patients with Parkinson's disease
}

\author{
Manal Mahmoud El-Kattann ${ }^{1}$, Soheir Mohammed Esmat ${ }^{2}$, Eman Hasan Esmail ${ }^{1}$, Heba Assem Deraz and \\ Rania Shehata Ismail $\left.\right|^{*}$
}

\begin{abstract}
Background: The changes in the different retinal layers in Parkinson's disease (PD) patients can be easily assessed using optical coherence tomography $(\mathrm{OCT})$. Our aim was to evaluate retinal structural changes in patients with PD using OCT. Structural measurements of the retinal nerve fiber layer (RNFL), macular and ganglion cell complex (GCC) thicknesses were obtained using spectral domain optical coherence tomography. Disease severity was assessed using Unified Parkinson Disease Rating Scale (UPDRS).

Results: Retinal nerve fiber layer parameters, except for the superonasal and inferonasal quadrants, were significantly reduced in PD patients compared to controls. All macular parameters and GCC thickness were also reduced in PD patients compared to controls. Hoehn and Yahr (HY) staging was inversely correlated with all macular parameters, GCC and temporal RNFL thicknesses. UPDRS score showed a significant negative correlation with macular volume, inferior and nasal parafoveal thicknesses, nasal and temporal RNFL thicknesses and GCC thickness. The disease duration was inversely correlated with macular volume, inferior and temporal parafoveal thicknesses and GCC thickness. Using the multivariate linear regression analysis, the HY scale was a significant predictor for both the average GCC thickness and the macular volume. The sensitivity and specificity of average GCC thickness and macular volume to detect disease severity were $58.8 \%, 86.7 \%, 64.7 \%$ and $86.7 \%$, respectively.
\end{abstract}

Conclusion: Parkinson's disease causes axonal damage in the RNFL along with retinal thinning that can be detected using SD-OCT. Patients with greater axonal damage tend to have longer duration of the disease and more severe PD symptoms.

Keywords: Parkinson's disease, Optical coherence tomography, Retinal nerve fiber layer, Retinal ganglion cells, Macular thickness

\section{Background}

Parkinson's disease (PD) is a progressive neurodegenerative disorder characterized by motor symptoms, such as bradykinesia, rigidity, resting tremor, and postural instability. However, the loss of dopaminergic neurons also leads to non-motor alterations, such as depression, dementia, and autonomic dysfunction [1].

\footnotetext{
*Correspondence: raniashehata.neuro@yahoo.com

${ }^{1}$ Department of Neurology, Faculty of Medicine, Cairo University, Giza,

Egypt

Full list of author information is available at the end of the article
}

Vision is one of the non-motor systems altered in PD. Patients suffering from PD are reported to have decreased visual acuity, contrast sensitivity, and color vision [2].

Optical coherence tomography (OCT) was one of the biggest advances in ophthalmic imaging [3]. It provides cross-sectional images of the retina and optic disc based on interference patterns produced by low coherence light reflected from retinal tissues. This technology includes the development of parameters to provide quantitative, objective, and reproducible measurements of the different retinal layers [4]. 
Prior researchers have demonstrated that parameters provided by OCT are accurate to detect various inner retinal or optic nerve pathologies, such as multiple sclerosis, PD, or Alzheimer disease [5]. The retinal nerve fiber layer (RNFL) includes mainly non-myelinated axons of retinal ganglion cells (RGCs), so it offers direct assessment of the axons in patients with PD [4]. Moreover, measurement of the RGC layer provides more accurate information about axonal loss in neurodegenerative diseases [6]. Studies in PD have further correlated retinal alterations including macular, ganglion cell layer, and RNFL defects with PD severity and duration. These studies demonstrated the potential role of OCT as a tool to monitor disease severity and progression in PD $[7,8]$.

This study aimed to measure the thicknesses of the macula, retinal nerve fiber layer and ganglion cell complex in patients with Parkinson's disease compared to healthy controls using OCT and to correlate the values measured by the OCT with the clinical and ophthalmological parameters.

\section{Methods}

This case-control study included 62 subjects, conducted between February 2019 to December 2019. Written consents were taken from patients prior to participation.

Participants were divided into two groups: group (1) included 32 patients with established PD and group (2) (Controls) included 30 age- and sex-matched healthy subjects as controls.

Included in this study: patients with PD who fulfilled the criteria for diagnosis of idiopathic PD based on MDS clinical diagnostic criteria for Parkinson's disease, 2015 [9]. Their age ranged from 40 to 70 years. Both sexes were included.

Excluded from this study: presence of significant refractive error such as high myopia, local ocular disease such as glaucoma, diabetic retinopathy or media opacification and history of ocular trauma or ocular surgery.

All patients in this study were submitted to the following: neurological examination, ophthalmological assessment including calculation of the best corrected visual acuity (BCVA) using Log Mar and evaluation of color vision by the Ishihara's chart, evaluation and staging of PD using UPDRS and HY staging. Measurement of the thicknesses of the macula, retinal nerve fiber layer and ganglion cell complex using spectral domain optical coherence tomography (SD-OCT). It was performed using The Optovue RTVue ${ }^{\mathrm{TM}} 100$ (Optovue Inc., Fremont, CA, USA) OCT machine. It was conducted in the Investigative and Laser Unit of the Ophthalmology Department.

Statistical analysis: The collected data were coded, tabulated, and statistically analyzed using IBM SPSS statistics (Statistical Package for Social Sciences) software version 22.0, IBM Corp., Chicago, USA, 201. Data were summarized using mean, standard deviation, median, minimum and maximum in quantitative data and using frequency (count) and relative frequency (percentage) for categorical data. Comparisons between quantitative variables were done using unpaired $t$ test. For comparing categorical data, Chi-square $\left(\chi^{2}\right)$ test was performed. Exact test was used instead when the expected frequency is less than 5 . Correlations between quantitative variables were done using Spearman correlation coefficient. Linear regression analysis was done to predict some variables using different OCT parameters. ROC curve was performed to detect best cut-off value of GCC and macular volume for detection of severe cases. $p$-values less than 0.05 were considered as statistically significant.

\section{Results}

The age of PD patients ranged from 40 to 70 years, with a mean age of $61.12 \pm 6.24$ SD. In the control group, the age ranged from 42 to 67 years with a mean age of $56.90 \pm 6.96$ SD. There were 23 males $(71.9 \%)$ and 9 females $(28.1 \%)$ among PD patients. In the control group, there were 20 males (66.7\%) and 10 females (33.3\%). There was no statistically significant difference between the two groups regarding age and gender $(p$ value $=0.31$, $0.56)$, respectively.

The duration of illness in patients with PD ranged from 0.5 to 11 years with mean disease duration $3.94 \pm 2.41$ SD.

The total UPDRS score ranged from 26 to 78 with mean score of $48.59 \pm 14.93$ SD. The Hoehn and Yahr (HY) scale ranged from 1.5 to 5 with mean $2.80 \pm 0.83$ SD. The median HY stage was III.

In the current study, $75 \%$ of cases received treatment (71.9\% in the form of dopaminergic drugs including levodopa and DA agonists). $25 \%$ of cases were untreated.

The best corrected visual acuity (BCVA) ranged from 0.00 to 0.80 with mean of $0.28 \pm 0.18 \mathrm{SD}$ in patients with PD. Color vision was normal in all PD patients.

Demographic and clinical characteristics of the studied groups are illustrated in Table 1.

A statistically significantly difference was found between PD patients and healthy controls regarding BCVA being worse in patients with PD $(p$ value $<0.001)$, whereas no difference was found between the two groups regarding assessment of color vision using the Ishihara's color test.

The SD-OCT measurements revealed significant differences in most of the RNFL sectors between PD patients and healthy controls, except for the superonasal and inferonasal RNFL thicknesses. Macular thickness and volume, and GCC thickness were also significantly reduced 
Table 1 Demographic and clinical data of the studied groups

\begin{tabular}{lllr}
\hline & Patients & Control & $\boldsymbol{p}$ value \\
\hline $\begin{array}{l}\text { Age (year) } \\
\text { Gender }\end{array}$ & $61.12 \pm 6.24$ & $56.90 \pm 6.96$ & 0.31 \\
$\quad$ Male & $23(71.9 \%)$ & $20(66.7 \%)$ & \\
$\quad$ Female & $9(28.1 \%)$ & $10(33.3 \%)$ & 0.56 \\
Duration (year) & $3.94 \pm 2.41 \mathrm{SD}$ & - & \\
Total UPDRS score & $48.59 \pm 14.93$ & - & \\
H\&Y scale & $2.80 \pm 0.83$ & - & $<0.001^{*}$ \\
BCVA (LogMAR) & $0.28 \pm 0.18$ & $0.12 \pm 0.09$ & \\
\hline
\end{tabular}

UPDRS Unified Parkinson's Disease Rating Scale, HY Hoehn and Yahr, BCVA best corrected visual acuity, LogMAR logarithm of the minimal angle of resolution *Statistically significant

in patients with PD compared to healthy controls (Table 2).

There was no significant difference in the OCT parameters between the treated and untreated PD patients.

The BCVA (using Log Mar) showed a statistically significant negative correlation with the nasal parafoveal thickness $(r=-0.435, p$ value $=0.013)$ (Fig. 1). However, there was no statistically significant correlation between the BCVA and the rest of the OCT parameters.

There was a statistically significant negative correlation between the duration of the disease and the macular volume, inferior and temporal parafoveal thicknesses and GCC thickness.

The UPDRS scores showed a statistically significant negative correlation with the macular volume, inferior and nasal parafoveal thicknesses, nasal and temporal RNFL thicknesses as well as the GCC thickness. Moreover, there was a statistically significant negative correlation between the HY scores and all the macular thickness parameters, GCC thickness and the temporal RNFL thickness.

Correlations between the duration of the disease, the total UPDRS score, HY staging and OCT parameters are shown in Table 3.

The multivariate linear regression analysis was used to detect the predictors for each of the average GCC thickness, macular volume and average RNFL thickness (dependent factors). The duration of the disease and disease severity assessed by total UPDRS and HY scale were used as independent predictors in the models. We found that the HY scale was a significant predictor for both the average GCC thickness and the macular volume $(\beta=-0.523, p$ value $=0.002)$ $(\beta=-0.496, p$ value $=0.004)$, respectively (Tables 4,5$)$.

Sensitivity and specificity of average GCC thickness and macular volume in detection of disease severity: we observed that at a cut-off point value of $<86.65$, the sensitivity and specificity of average GCC thickness

Table 2 SD-OCT parameters in PD patients versus controls

\begin{tabular}{|c|c|c|c|}
\hline & $\begin{array}{l}\text { Patients } \\
\text { Mean } \pm \text { SD }\end{array}$ & $\begin{array}{l}\text { Controls } \\
\text { Mean } \pm \text { SD }\end{array}$ & $p$ value \\
\hline \multicolumn{4}{|l|}{ RNFL thickness ( $\mu \mathrm{m})$} \\
\hline Superonasal & $117.74 \pm 22.35$ & $123.50 \pm 20.51$ & 0.299 \\
\hline Inferonasal & $121.27 \pm 23.29$ & $130.60 \pm 25.20$ & 0.138 \\
\hline Nasal & $78.6 \pm 9.2$ & $85.57 \pm 13.36$ & $0.021^{*}$ \\
\hline Superior temporal & $127.79 \pm 17.11$ & $138.73 \pm 16.34$ & $0.013^{*}$ \\
\hline Inferior temporal & $128.95 \pm 23.07$ & $145.45 \pm 22.14$ & $0.006^{*}$ \\
\hline Temporal & $79.23 \pm 12.97$ & $87.02 \pm 9.57$ & $0.01^{*}$ \\
\hline \multicolumn{4}{|l|}{ Macular measurements } \\
\hline Foveal thickness $(\mu \mathrm{m})$ & $232.5 \pm 20.83$ & $248.4 \pm 19.46$ & $0.003^{*}$ \\
\hline Superior parafoveal thickness $(\mu \mathrm{m})$ & $297.3 \pm 31.46$ & $317.62 \pm 16.07$ & $0.002^{*}$ \\
\hline Inferior parafoveal thickness ( $\mu \mathrm{m})$ & $299.55 \pm 23.86$ & $315.9 \pm 18.38$ & $0.004^{*}$ \\
\hline Nasal parafoveal thickness ( $\mu \mathrm{m})$ & $292.69 \pm 36.95$ & $317.43 \pm 17.21$ & $0.001^{*}$ \\
\hline Temporal parafoveal thickness $(\mu m)$ & $288.92 \pm 24.49$ & $303.05 \pm 15.27$ & $0.008^{*}$ \\
\hline Macular volume $\left(\mathrm{mm}^{3}\right)$ & $6.75 \pm 0.54$ & $7.16 \pm 0.37$ & $0.001^{*}$ \\
\hline \multicolumn{4}{|l|}{ GCC thickness $(\mu \mathrm{m})$} \\
\hline Average thickness & $90.25 \pm 9.58$ & $98.85 \pm 11.52$ & $0.002^{*}$ \\
\hline Superior thickness & $90.73 \pm 10.2$ & $98.57 \pm 10.8$ & $0.005^{*}$ \\
\hline Inferior thickness & $89.79 \pm 9.35$ & $99.13 \pm 12.44$ & $0.001^{*}$ \\
\hline
\end{tabular}

RNFL retinal nerve fiber layer, GCC ganglion cell complex

*Statistically significant 


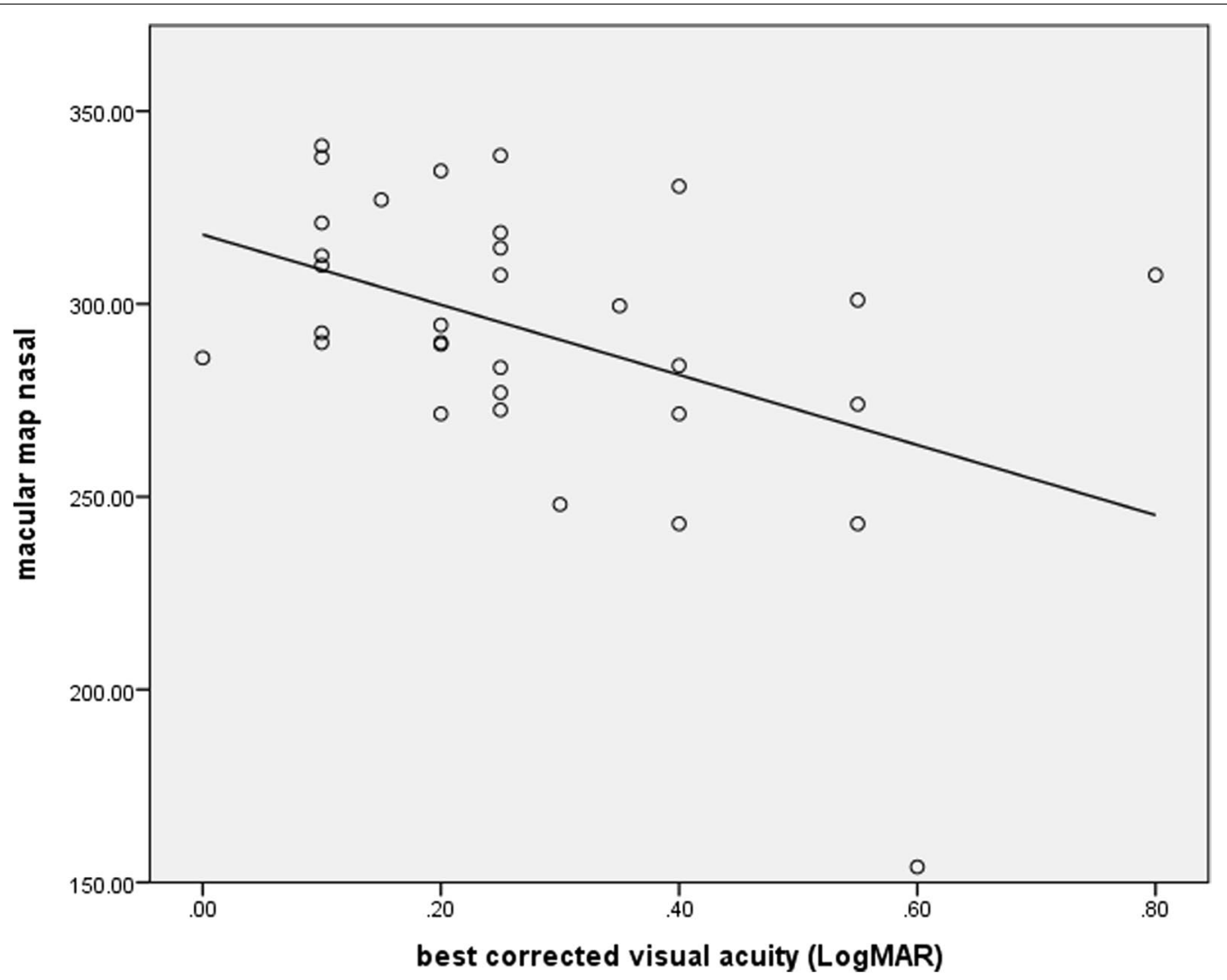

Fig. 1 Correlation between visual acuity and OCT parameters. OCT optical coherence tomography

Table 3 Correlations between the duration of the disease, the total UPDRS score, HY staging and OCT parameters

\begin{tabular}{|c|c|c|c|c|c|c|}
\hline \multirow[t]{2}{*}{ OCT parameters } & \multicolumn{2}{|c|}{ Duration of disease (years) } & \multicolumn{2}{|c|}{ UPDRS scores } & \multicolumn{2}{|c|}{ HY staging } \\
\hline & $(r)$ & $p$ value & $(r)$ & $p$ value & $(r)$ & $p$ value \\
\hline \multicolumn{7}{|l|}{ RNFL thickness } \\
\hline Superonasal & -0.221 & 0.232 & -0.077 & 0.682 & 0.003 & 0.987 \\
\hline Inferonasal & -0.201 & 0.278 & -0.108 & 0.564 & -0.028 & 0.879 \\
\hline Nasal & -0.335 & 0.065 & -0.389 & $0.030^{*}$ & -0.250 & 0.175 \\
\hline Superior temporal & -0.308 & 0.092 & -0.210 & 0.258 & -0.241 & 0.191 \\
\hline Inferior temporal & -0.319 & 0.080 & -0.328 & 0.072 & -0.399 & 0.026 \\
\hline Temporal & -0.259 & 0.160 & -0.371 & $0.040^{*}$ & -0.413 & $0.021^{*}$ \\
\hline \multicolumn{7}{|l|}{ Macular measurements } \\
\hline Central foveal thickness & -0.304 & 0.091 & -0.329 & 0.066 & -0.441 & $0.011^{*}$ \\
\hline Superior parafoveal thickness & -0.337 & 0.059 & -0.219 & 0.228 & -0.433 & $0.013^{*}$ \\
\hline Inferior parafoveal thickness & -0.387 & $0.029^{*}$ & -0.391 & $0.027^{*}$ & -0.605 & $<0.001^{*}$ \\
\hline Nasal parafoveal thickness & -0.341 & 0.056 & -0.391 & $0.027^{*}$ & -0.649 & $<0.001^{*}$ \\
\hline Temporal parafoveal thickness & -0.401 & $0.023^{*}$ & -0.321 & 0.073 & -0.544 & $0.001^{*}$ \\
\hline Macular volume & -0.411 & $0.019^{*}$ & -0.458 & $0.008^{*}$ & -0.545 & $0.001^{*}$ \\
\hline \multicolumn{7}{|l|}{ GCC thickness } \\
\hline Average & -0.403 & $0.022^{*}$ & -0.484 & $0.005^{*}$ & -0.511 & $0.003^{*}$ \\
\hline Superior & -0.421 & $0.017^{*}$ & -0.476 & $0.006^{*}$ & -0.482 & $0.005^{*}$ \\
\hline Inferior & -0.358 & $0.044^{*}$ & -0.460 & $0.008^{*}$ & -0.515 & $0.003^{*}$ \\
\hline
\end{tabular}

UPDRS Unified Parkinson's Disease Rating Scale, HY Hoehn and Yahr, OCT optical coherence tomography, RNFL retinal nerve fiber layer, GCC ganglion cell complex *Statistically significant 
Table 4 Linear regression model of the average GCC thickness

\begin{tabular}{|c|c|c|c|c|c|c|c|}
\hline \multirow[t]{2}{*}{ Coefficients $^{a}$} & \multicolumn{2}{|c|}{ Unstandardized coefficients } & \multirow{2}{*}{$\begin{array}{l}\text { Standardized } \\
\text { coefficients } \\
\text { Beta }\end{array}$} & \multirow[b]{2}{*}{$t$} & \multirow[b]{2}{*}{$p$ value } & \multicolumn{2}{|c|}{$95.0 \%$ confidence interval for B } \\
\hline & B & Std. error & & & & Lower bound & Upper bound \\
\hline (Constant) & 107.118 & 5.227 & & 20.494 & $0.000^{*}$ & 96.444 & 117.792 \\
\hline HY scale & -6.032 & 1.794 & -0.523 & -3.363 & $0.002^{*}$ & -9.695 & -2.369 \\
\hline
\end{tabular}

HY Hoehn and Yahr

a Dependent variable: average GCC thickness

*Statistically significant

Table 5 Linear regression model of the macular volume

\begin{tabular}{|c|c|c|c|c|c|c|c|}
\hline \multirow[t]{2}{*}{ Coefficients $^{a}$} & \multicolumn{2}{|c|}{ Unstandardized coefficients } & \multirow{2}{*}{$\begin{array}{l}\text { Standardized } \\
\text { coefficients } \\
\text { Beta }\end{array}$} & \multirow[b]{2}{*}{$t$} & \multirow[b]{2}{*}{$p$ value } & \multicolumn{2}{|c|}{$95.0 \%$ confidence interval for $B$} \\
\hline & B & Std. error & & & & Lower bound & Upper bound \\
\hline (Constant) & 7.646 & 0.298 & & 25.689 & $0.000^{*}$ & 7.038 & 8.254 \\
\hline HY scale & -0.320 & 0.102 & -0.496 & -3.131 & $0.004^{*}$ & -0.528 & -0.111 \\
\hline
\end{tabular}

HY Hoehn and Yahr

a Dependent variable: macular volume

*Statistically significant

were $58.8 \%$ and $86.7 \%$, respectively $(\mathrm{AUC}=0.74, p$ value $=0.006)$; at a cut-off point value of $<6.61$, the sensitivity and specificity of macular volume were $64.7 \%$ and 86.7\%, respectively (AUC $=0.82, p$ value $\leq 0.001$ ) (Fig. 2).

\section{Discussion}

Neurodegeneration in PD is not restricted to the brain, but also occurs in the retina. Accordingly, patients with PD can gradually develop visual problems. The changes in the different retinal layers can be easily assessed using OCT [4]. In the current study, SD-OCT was used as a quantitative measure to evaluate retinal structures and morphology in patients with PD.

The present study revealed reduced macular thickness and macular volume in patients with PD compared with healthy controls. This was in agreement with previous studies that reported thinning of macula $[6,10-15]$.

The current study also revealed reduced GCC thickness in patients with PD compared to healthy controls. This was in agreement with Moschos and Chatziralli (2017) [13] who reported a significant reduction in the average GCC thickness in patients with PD compared to controls. Other studies using segmentation analysis also observed significant thinning of the GCL in patients with PD $[8,16]$. GCL atrophy is thought to be a component of RNFL loss, which is suggested to produce consecutive degeneration of the RGC layer and its axons as the disease progresses $[17,18]$.
The results of our study revealed reduction in the RNFL thickness in the temporal, superotemporal, inferotemporal and nasal quadrants in PD patients compared to healthy controls. However, our study could not find differences regarding the thicknesses of the superonasal and inferonasal quadrants between the two groups. This was supported by the first OCT study in PD by Inzelberg et al. (2004) [19] who reported thinned average RNFL, specifically in the inferior and temporal quadrants in a small group of 10 PD patients. Satue et al. (2013) [15] further revealed significant differences in the inferior, inferotemporal and superotemporal RNFL thicknesses in patients with PD compared to controls using SD-OCT. Moreover, Moschos and Chatziralli [13] observed a significant reduction in the average RNFL thickness as well as the superior and temporal quadrants, in PD patients compared to controls. The significant reduction in the temporal fibers may suggest a mitochondrial pattern of retinal axonal loss in PD. This may support the role of mitochondrial dysfunction in the pathogenesis of $\mathrm{PD}$ [20]. Other studies showed significant RNFL thinning in PD patients in all quadrants [21-24].

The RNFL comprises mainly non-myelinated axons of RGCs, so RNFL thickness measurements provide a relatively direct assessment of the axons and axonal damage. PD causes axonal damage in the RNFL, along with retinal thinning that can be detected using SD-OCT [4].

Contrary to our study, some studies have failed to find changes in the inner macular thickness or macular 


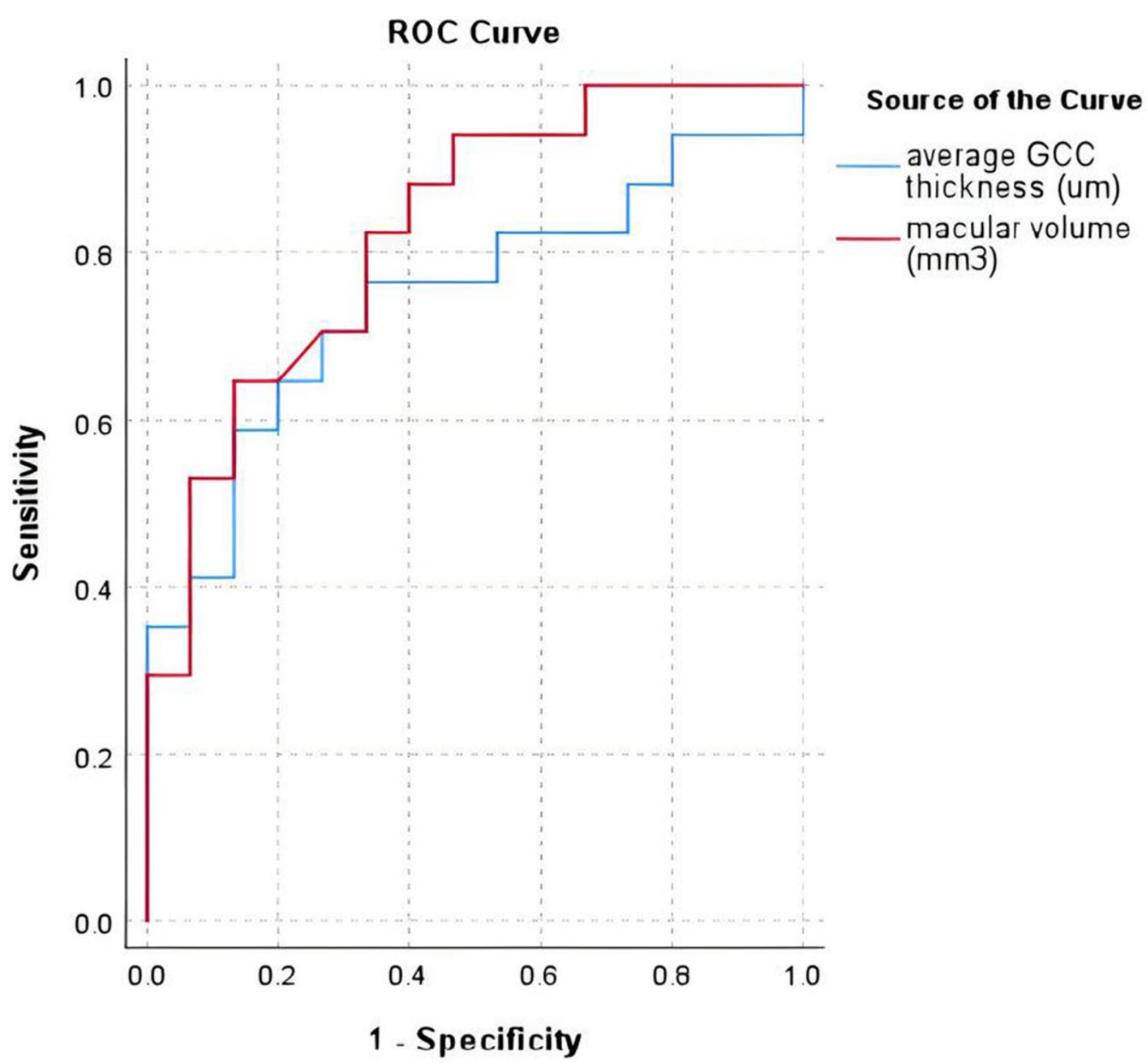

Fig. 2 ROC curves for of average GCC thickness and macular volume as biomarkers to detect disease severity in patients with PD. GCC ganglion cell complex; PD Parkinson's disease

volume [25-27]. Sen et al. (2014) [28] also reported no significant difference in the average GCC thickness among patients with PD and controls. Moreover, some studies did not find difference in the RNFL thickness between PD patients and healthy controls $[25,27,29$, 30]. This discrepancy may be explained by the different OCT equipment used by these studies, which can affect retinal measurements. Different sample sizes and retinal segmentation algorithms may account for these discrepant findings.

The results of our study revealed that long duration of the disease was associated with decreased macular volume, inferior and temporal parafoveal thicknesses and GCC thickness. This was in agreement with a study conducted by Garcia-Martin et al. (2014) [7] which revealed that the inner retinal layer thicknesses was significantly thinner in PD patients with disease duration longer than 10 years compared to those with shorter disease duration. This study reported that thickness inversely correlated with longer disease duration.

The results of our study also showed a significant negative correlation between the UPDRS scores and the macular volume, inferior and nasal parafoveal thicknesses, as well as the GCC measurements, and nasal and temporal RNFL thicknesses. Our results are supported by a study done by Altintaş et al. (2008) [14] who reported an inverse correlation between the foveal thickness measured by TD-OCT and the UPDRS total and motor scores. Another study conducted by Satue et al. (2014) [6] revealed an inverse correlation between the inner inferior macular thickness measured using the Cirrus OCT device and the UPDRS scores.

The results of our study also revealed a significant inverse correlation between all macular thickness measurements, GCC thickness and temporal RNFL thickness assessed by SD-OCT and the scores on the HY scale. In agreement with our study, Garcia-Martin et al. (2014) 
[12] reported that both the RNFL and macular thicknesses were negatively correlated with the HY scores. Pilat et al. (2016) [23] also reported a negative correlation between the RNFL and central retinal thicknesses and the HY scores. Moreover, Satue et al. (2014) [6] found that most macular thickness measurements assessed by Spectralis OCT are correlated with the HY scores.

Contrary to our study, some studies failed to detect correlations between structural parameters using OCT and disease duration or severity assessed by either HY scale or UPDRS [8, 20, 30-32].

These discrepant findings may be partly explained by the difference in terms of the stage and severity of the disease. In the study conducted by Aydin et al. (2017) [32], the median HY score of PD patients was 1 and the median UPDRS score was 24, while the median HY score was 3 and the median UPDRS score was 49.5 in our study. Also, La Morgia et al. (2013) and Roth et al. (2014) [20, 30] included patients with mild disease (mean UPDRS scores were $25.9 \pm 12.4$ and $19 \pm 10$, respectively). In our study, the mean UPDRS score was $48.59 \pm 14.94$. Moreover, Aydin et al. (2017) [32] included a relatively small number of patients (25 PD patients) and 29 healthy controls which may account for some of the discrepant results.

The results of our study revealed no significant difference in the OCT parameters between the treated and untreated patients with PD. Previous researchers did not find significant correlations between retinal thickness and levodopa dosages [26, 33]. Sen et al. (2014) [28] found no significant difference in the thickness of retina between the treated and untreated groups although the disease in patients with treated PD was more severe than in the untreated group. They suggested that levodopa may have a protective effect on retina in patients with PD.

In addition, by using the multivariate linear regression analysis, we found that the HY scale was a significant predictor for the reduction of the average GCC thickness and macular volume.

The main limitations of the study included that it would be of more interest if we could compare the RNFL thinning pattern in PD patients with that of secondary parkinsonism, a longitudinal study using repeated OCT on the same patients will offer better data on the course of the disease, and we did not have the opportunity to use electroretinogram (ERG) due to financial issues and hence could not evaluate the functional impairment in visual processing along with OCT changes.

\section{Conclusion}

In conclusion, PD causes axonal damage in the RNFL along with retinal thinning that can be detected using SD-OCT. Patients with greater axonal damage tend to have longer duration of the disease and more severe PD symptoms. The HY scale was a significant predictor for reduction of the average GCC thickness and the macular volume. OCT is a non-invasive, inexpensive and fast procedure, and frequent evaluation of retinal structures by OCT may be useful for detecting disease progression and monitoring treatment effectiveness.

\section{Abbreviations \\ BCVA: Best Corrected Visual Acuity; GCC: Ganglion cell complex; OCT: Optical coherence tomography; PD: Parkinson's disease; RNFL: Retinal nerve fiber layer; SD-OCT: Spectral domain optical coherence tomography; UPDRS: Uni- fied Parkinson Disease Rating Scale.}

\section{Acknowledgements}

The authors acknowledge subjects for their participation and cooperation in this study.

\section{Authors' contributions}

MME: research idea and conception, data acquisition, data analysis and interpretation, SME: performing and reviewing the laboratory workup, EHE: data acquisition, data analysis and interpretation, HAD: data acquisition, data analysis and interpretation RSI: data acquisition, data analysis and data interpretation, and manuscript writing and reviewing. All authors have read and approved the manuscript.

\section{Funding}

This research received no specific grant from any funding agency in the public, commercial, or not-for-profit sectors.

\section{Availability of data and materials}

The datasets generated and/or analyzed during the current study are not publicly available due to current Cairo University regulations and Egyptian legislation, but are available from the corresponding author on reasonable request and after institutional approval.

\section{Declarations}

\section{Ethics approval and consent to participate}

The aim and procedures of the study were explained to every participant and an informed written consent was obtained from all participants before being enrolled in the study. The study was approved by the ethical committee of the Neurology Department, Cairo University Hospitals (25/4/2017).

\section{Consent for publication}

Not applicable.

\section{Competing interests}

The authors declare that they have no competing interests (financial and non-financial). We declare that the research was conducted in absence of any commercial relationships that could be constructed as a potential conflict of interest.

\section{Author details}

${ }^{1}$ Department of Neurology, Faculty of Medicine, Cairo University, Giza, Egypt. ${ }^{2}$ Department of Ophthalmology, Faculty of Medicine, Cairo University, Giza, Egypt.

Received: 23 July 2021 Accepted: 24 November 2021

Published online: 12 February 2022

References

1. Park A, Stacy M. Non-motor symptoms in Parkinson's disease. J Neurol. 2009:256(3):293-8. 
2. Spaide RF, Fujimoto JG, Waheed NK, Sadda SR, Staurenghi G. Optical coherence tomography angiography. Prog Retin Eye Res. 2018;64:1-55.

3. Weil RS, Schrag AE, Warren JD, Crutch SJ, Lees AJ, Morris HR. Visual dysfunction in Parkinson's disease. Brain. 2016;139(11):2827-43.

4. Sakata LM, DeLeon-Ortega J, Sakata V, Girkin CA. Optical coherence tomography of the retina and optic nerve-a review. Clin Exp Ophthalmol. 2009;37(1):90-9.

5. Satue M, Obis J, Rodrigo MJ, Otin S, Fuertes MI, Vilades E, et al. Optical coherence tomography as a biomarker for diagnosis, progression, and prognosis of neurodegenerative diseases. J Ophthalmol. 2016. https:// doi.org/10.1155/2016/8503859.

6. Satue M, Seral M, Otin S, Alarcia R, Herrero R, Bambo MP, et al. Retinal thinning and correlation with functional disability in patients with Parkinson's disease. Br J Ophthalmol. 2014;98(3):350-5.

7. Garcia-Martin E, Larrosa JM, Polo V, Satue M, Marques ML, Alarcia R, et al. Distribution of retinal layer atrophy in patients with Parkinson disease and association with disease severity and duration. Am J Ophthalmol. 2014;157(2):470-8.

8. Sari ES, Koc R, Yazici A, Sahin G, Ermis SS. Ganglion cell-inner plexiform layer thickness in patients with Parkinson disease and association with disease severity and duration. J Neuro ophthalmol. 2015;35(2):117-21.

9. Postuma RB, Berg D, Stern M, Poewe W, Olanow CW, Oertel W, et al. MDS clinical diagnostic criteria for Parkinson's disease. Mov Disord. 2015;30(12):1591-601.

10. Adam CR, Shrier E, Ding Y, Glazman S, Bodis-Wollner I. Correlation of inner retinal thickness evaluated by spectral-domain optical coherence tomography and contrast sensitivity in Parkinson disease. J Neuro ophthalmol. 2013;33(2):137-42.

11. Spund B, Ding Y, Liu T, Selesnick I, Glazman S, Shrier EM, et al. Remodeling of the fovea in Parkinson disease. J Neural Transm. 2013;120(5):745-53.

12. Garcia-Martin E, Rodriguez-Mena D, Satue M, Almarcegui C, Dolz I, Alarcia $\mathrm{R}$, et al. Electrophysiology and optical coherence tomography to evaluate Parkinson disease severity. Invest Ophthalmol Vis Sci. 2014;55(2):696-705.

13. Mailankody P, Battu R, Khanna A, Lenka A, Yadav R, Pal PK. Optical coherence tomography as a tool to evaluate retinal changes in Parkinson's disease. Parkinsonism Relat Disord. 2015;21(10):1164-9.

14. Altintaş Ö, Işeri P, Özkan B, Çağlar Y. Correlation between retinal morphological and functional findings and clinical severity in Parkinson's disease. Doc Ophthalmol. 2008;116(2):137-46.

15. Satue M, Garcia-Martin E, Fuertes I, Otin S, Alarcia R, Herrero R, et al. Use of Fourier-domain OCT to detect retinal nerve fiber layer degeneration in Parkinson's disease patients. Eye. 2013;27(4):507-14.

16. Bayhan HA, Aslan Bayhan S, Tanık N, Gürdal C. The association of spectraldomain optical coherence tomography determined ganglion cell complex parameters and disease severity in Parkinson's disease. Curr Eye Res. 2014;39(11):1117-22.

17. Almarcegui C, Dolz I, Pueyo V, Garcia E, Fernandez FJ, Martin J, et al. Correlation between functional and structural assessments of the optic nerve and retina in multiple sclerosis patients. Neurophysiol Clin. 2010;40(3):129-35.

18. Davies EC, Galetta KM, Sackel DJ, Talman LS, Frohman EM, Calabresi PA, et al. Retinal ganglion cell layer volumetric assessment by spectraldomain optical coherence tomography in multiple sclerosis: application of a high-precision manual estimation technique. J Neuro ophthalmol. 2011;31(3):260-4.

19. Inzelberg R, Ramirez JA, Nisipeanu P, Ophir A. Retinal nerve fiber layer thinning in Parkinson disease. Vision Res. 2004;44(24):2793-7.

20. La Morgia C, Barboni P, Rizzo G, Carbonelli M, Savini G, Scaglione C, et al. Loss of temporal retinal nerve fibers in Parkinson disease: a mitochondrial pattern? Eur J Ophthalmol. 2013;20(1):198-201.

21. Ascaso F, Jimenez B, del Val JL, Lozano IP, Perez-Garcia D, Ibanez-Alperte J, et al. Is retinal optical coherence tomography an imaging biomarker for Parkinson disease? Invest Ophthalmol Vis Sci. 2013;54(15):1435.

22. Jiménez B, Ascaso FJ, Cristóbal JA, López del Val J. Development of a prediction formula of Parkinson disease severity by optical coherence tomography. Mov Disord. 2014;29(1):68-74.

23. Pilat A, McLean RJ, Proudlock FA, Maconachie GD, Sheth V, Rajabally YA, et al. In vivo morphology of the optic nerve and retina in patients with Parkinson's disease. Invest Ophthalmol Vis Sci. 2016;57(10):4420-7.
24. Chrysou A, Jansonius NM, Van Laar T. Retinal layers in Parkinson's disease: a meta-analysis of spectral-domain optical coherence tomography studies. Parkinsonism Relat Disord. 2019;64:40-9.

25. Archibald NK, Clarke MP, Mosimann UP, Burn DJ. Retinal thickness in Parkinson's disease. Parkinsonism Relat Disord. 2011;17(6):431-6.

26. Lee JY, Kim JM, Ahn J, Kim HJ, Jeon BS, Kim TW. Retinal nerve fiber layer thickness and visual hallucinations in Parkinson's disease. Mov Disord. 2014;29(1):61-7.

27. Kopal A, Mejzlíková E, Preiningerová JL, Brebera D, Ulmanová O, Ehler E et al. Changes of retina are not involved in the genesis of visual hallucinations in Parkinson's disease. Parkinson's Dis. 2015. https://doi.org/10.1155/ 2015/709191.

28. Sen A, Tugcu B, Coskun C, Ekinci C, Nacaroglu SA. Effects of levodopa on retina in Parkinson disease. Eur J Ophthalmol. 2014:24(1):114-9.

29. Tsironi EE, Dastiridou A, Katsanos A, Dardiotis E, Veliki S, Patramani G, et al. Perimetric and retinal nerve fiber layer findings in patients with Parkinson's disease. BMC Ophthalmol. 2012;12(1):1-7.

30. Roth NM, Saidha S, Zimmermann H, Brandt AU, Isensee J, BenkhelloufRutkowska A, et al. Photoreceptor layer thinning in idiopathic Parkinson's disease. Mov Disord. 2014;29(9):1163-70.

31. Chorostecki J, Seraji-Bozorgzad N, Shah A, Bao F, Bao G, George E, et al. Characterization of retinal architecture in Parkinson's disease. J Neurol Sci. 2015;355(1-2):44-8

32. Aydin TS, Umit D, Nur OM, Fatih U, Asena K, Nefise OY, et al. Optical coherence tomography findings in Parkinson's disease. Kaohsiung J Med Sci. 2018;34(3):166-71.

33. Cubo E, Peña MJ, Varela ED, Gil OP, Gutierrez PG, González EA, et al. Lack of association of morphologic and functional retinal changes with motor and non-motor symptoms severity in Parkinson's disease. J Neural Transm. 2014;121(2):139-44.

\section{Publisher's Note}

Springer Nature remains neutral with regard to jurisdictional claims in published maps and institutional affiliations.

\section{Submit your manuscript to a SpringerOpen ${ }^{\circ}$ journal and benefit from:}

- Convenient online submission

- Rigorous peer review

- Open access: articles freely available online

- High visibility within the field

- Retaining the copyright to your article

Submit your next manuscript at springeropen.com 